\title{
Phosphatase Activity in T-Mycoplasmas
}

\author{
F. T. BLACK \\ Institute of Medical Microbiology, University of Aarhus, DK 8000, Aarhus C, Denmark
}

\begin{abstract}
Phosphatase activity was demonstrated in $44 \mathrm{~T}$-mycoplasmas tested. The phosphatase test was carried out both on a solid and in a liquid medium, the latter being more sensitive. The presence of both acid and alkaline phosphatases was indicated. The test was found to be unsuitable for the differentiation of T-mycoplasmas, since all strains were positive.
\end{abstract}

The phosphatase test has been reported by Aluotto et al. (1) and Bürger et al. (3) to be valuable for differentiating between $\mathrm{Myco}$ plasma species, whereas Williams and Wittler (6) found it to give only weak and variable reactions within the genus Acholeplasma and therefore to be not very useful from a taxonomic viewpoint.

This study was carried out to test the T-mycoplasmas for phosphatase activity and to determine the possible value of the phosphatase test in differentiating T-mycoplasmas.

Organisms. Forty-four T-mycoplasma strains were studied: representatives of $\mathbf{8}$ serotypes of human T-mycoplasmas (2), 35 untyped human strains isolated from the vagina, pharynx, and male urethra and 1 bovine strain (A 417-T-2), kindly supplied by R. N. Gourlay (Campton, New bury, Berkshire).

$M$. orale II strain $\mathrm{CH} 20247$ was used as a positive test-control organism.

Media. The T-mycoplasmas were grown in a modified Shepard medium (S medium) consisting of Trypticase soy broth (BBL), 3\% wt/vol; horse serum, 20\%; yeast extract (baker's yeast), final concentration $2.5 \%$; and sodium penicillin, 1,500 international units per $\mathrm{ml}$; the $\mathrm{pH}$ was adjusted to 6.0 . $M$. orale II was grown in Hayflick medium.

Phosphatase test. The plate method was a slight modification of that described by Aluotto et al. (1). The medium consisted of Trypticase soy broth (BBL) supplemented with inactivated horse serum, 20\%; Ionagar no. 2 (Oxoid), 1.1\%; yeast extract, final concentration $2.5 \%$; sodium penicillin, 1,500 international units per $\mathrm{ml}$; and a sodium salt of phenolphthalein diphosphate (Sigma), 0.01\%; $\mathrm{pH}$ was adjusted to 6.0. Plates were inoculated in duplicate with $0.01 \mathrm{ml}$ of a log-phase broth culture and incubated for 3 days at $37 \mathrm{C}$ in $90 \%$ atmospheric air and $10 \% \mathrm{CO}_{2}$. After incubation the plates were tested by flooding the agar surface with $5 \mathrm{~N} \mathrm{NaOH}$. The appearance of a red color indicated phosphatase activity. Plates inoculated with $\mathbf{S}$ medium were used as negative test controls.

The liquid medium method was performed as follows. A log-phase culture grown in $100 \mathrm{ml}$ of $S$ medium was harvested in a Sorvall RC $2 b$ high-speed centrifuge at $20,000 \mathrm{rpm}$ for $1 \mathrm{~h}$. When not otherwise stated, the pellet was suspended in $1 \mathrm{ml}$ of phosphate-buffered saline, pH 6.5 , containing $0.01 \%$ of a sodium salt of phenolphthalein diphosphate. After incubation at $37 \mathrm{C}$ for $4 \mathrm{hr}$, two drops of $5 \mathrm{~N} \mathrm{NaOH}$ were added. The appearance of a red color indicated phosphatase activity. The pellet from $100 \mathrm{ml}$ of uninoculated $\mathbf{S}$ medium harvested as described above was used as a negative test control.

All 44 T-mycoplasma strains showed a positive reaction for phosphatase activity when tested with the plate method. Nine strains, including the bovine T-mycoplasma, were tested after growth in liquid medium, and all were found to be positive. $M$. orale II and uninoculated $\mathrm{S}$ medium gave a positive and a negative reaction, respectively, both on solid and in fluid medium.

The intensity of the red color depended on the number of mycoplasmas present. Plates inoculated with a culture containing less than $10^{5}$ colony-forming units per $\mathrm{ml}$ gave a negative or only a weakly positive reaction. Phosphatase activity could still be demonstrated in the pellet from $100 \mathrm{ml}$ of a culture containing $10^{4}$ colony-forming units per $\mathrm{ml}$.

It was possible to get a positive reaction for phosphatase at $\mathrm{pH} 5.4,6.5,7.4$, and 9.4 by using the liquid-medium technique, indicating the presence of both acid and alkaline phosphatases, as reported by Bürger et al. (3).

The only metabolic activities of the T-mycoplasmas reported so far are urease activity (5) 
and the production of a soluble hemolysin (4). The demonstration in the present study of phosphatase activity thus extends our sparse knowledge of the metabolism of the T-mycoplasmas; it may thereby be helpful in further investigations of the energy supply of these organisms.

Since the phosphatase test was positive for all strains tested, it is unsuitable for the differentiation of T-mycoplasmas, but it is a valuable test for the characterization of these organisms.

Any new isolates, especially from sources other than man, should be tested. The test on solid medium is simple to perform and hence usually preferable. However, when only sparse growth can be obtained, the liquid-medium test should be used because of the possibility of concentrating the organisms.

\section{REPRINT REQUESTS}

Address reprint requests to: Dr. Finn T. Black, Institute of Medical Microbiology, University of Aarhus, DK 8000 Aarhus C, Denmark.

\section{LITERATURE CITED}

1. Aluotto, B. B., R. G. Wittler, C. Q. Williams, and J. E. Faber. 1970. Standardized bacteriologic techniques for the characterization of Mycoplasma species. Int. J. Syst. Bacteriol. 20:35-58.

2. Black, F. T. 1970. Serological methods for classification of human T-mycoplasmas. 5th Int. Congr. Infec. Dis., Vienna, Austria 1:407-411.

3. Bürger, H., M. Doss, W. Mannheim, and A. Schüler. 1967. Studien zur biochemischen Differenzierung von Mycoplasmen. Z. Med. Mikrobiol. Immunol. 153:138-148.

4. Shepard, M. C. 1967. Cultivation and properties of T-strains of mycoplasma associated with nongonococcal urethritis. Ann. N.Y. Acad. Sci. 143:505-514.

5. Shepard, M. C., and C. D. Lunceford. 1967. Occurrence of urease in T-strains of mycoplasma. J. Bacteriol. 93: 1513-1520.

6. Williams, C. O., and R. G. Wittler. 1971. Hydrolysis of aesculin and phosphatase production by members of the order Mycoplasmatales which do not require sterol. Int. J. Syst. Bacteriol. 21:73-77. 